Article

\title{
Basalt FRP Spike Repairing of Wood Beams
}

\section{Luca Righetti ${ }^{1, *}$, Marco Corradi ${ }^{1,2}$ and Antonio Borri ${ }^{2}$}

1 Department of Mechanical and Construction Engineering, Northumbria University, Wynne-Jones Building, Newcastle upon Tyne NE1 8ST, UK; E-Mail: marco.corradi@ northumbria.ac.uk

2 Department of Engineering, University of Perugia, 92 Via Duranti, Perugia 06125, Italy; E-Mail: antonio.borri@unipg.it

* Author to whom correspondence should be addressed; E-Mail: luca.righetti@ northumbria.ac.uk; Tel.: +44-191-243-7649 (ext. 7649); Fax: +44-191-227-4561.

Academic Editor: Stephen C. Bondy

Received: 10 July 2015 / Accepted: 28 July 2015 / Published: 5 August 2015

\begin{abstract}
This article describes aspects within an experimental program aimed at improving the structural performance of cracked solid fir-wood beams repaired with Basalt Fiber Reinforced Polymer (BFRP) spikes. Fir wood is characterized by its low density, low compression strength, and high level of defects, and it is likely to distort when dried and tends to fail under tension due to the presence of cracks, knots, or grain deviation. The proposed repair technique consists of the insertion of BFRP spikes into timber beams to restore the continuity of cracked sections. The experimental efforts deal with the evaluation of the bending strength and deformation properties of 24 timber beams. An artificially simulated cracking was produced by cutting the wood beams in half or notching. The obtained results for the repaired beams were compared with those of solid undamaged and damaged beams, and increases of beam capacity, bending strength and of modulus of elasticity, and analysis of failure modes was discussed. For notched beams, the application of the BFRP spikes was able to restore the original bending capacity of undamaged beams, while only a small part of the original capacity was recovered for beams that were cut in half.
\end{abstract}

Keywords: softwood; basalt spikes; timber beams; bending test 


\section{Introduction}

Fir is a common softwood and a traditional construction material that has been extensively used in civil engineering for centuries. Construction using softwood is also an important part of infrastructure in many areas of the world: it can possibly be considered as one of the oldest construction materials, and its widespread use, from antiquity to the present, is essentially due to its high tensile strength, low weight density, large diffusion on the Earth, and good workability. However, softwood may be heavily affected by defects: natural defects (knots, shakes, cross grain), and defects caused during the treatment of felled timber may greatly reduce softwood's mechanical properties and, particularly, its tensile strength.

Cracks in softwood are produced by the seasoning and changing of moisture content, and are an important natural defect that mostly reduces the capacity of wood beams: as an orthotropic material, wood presents different shrinkage coefficients in the tangential and radial directions, and the compatibility of the deformation leads to the formation of cracks. For these reasons, it is very difficult to prevent the opening of cracks, and only a controlled, careful, and slow seasoning may contribute to reducing their formation.

The introduction of laminated softwood (glulam) has minimized this problem for new timber construction. Dimensional changes in the length, depth, and width, and crack formation of structural, glued laminated wood due to changes in moisture content have been greatly reduced.

On the other hand, there is difficulty in achieving a reliable solution to this problem for existing timber constructions, or when solid-sawn timber is used for new constructions. A controlled seasoning may minimize the formation of cracks in softwood before the use of the beams, but a sudden variation in temperature or air humidity can provoke the opening of cracks, decades after the use of the beams.

The structural reinforcement and repair of timber structures is often necessary for historic timber elements in order to comply with new standards. Existing timber beams have been commonly subjected, either to reinforcement or replacement with standard methods, involving the use of traditional construction materials, such as metals (aluminum, steel, etc.), or modern techniques with composite materials. The need for repair and improvement is typically very high for infrastructure: over $47 \%$ of the timber bridges in US are classified as structurally deficient in the National Bridge Inventory, based on visual inspection and the classification of defects [1].

In order to restore the continuity of cracked timber beams, several solutions have been proposed: the use of self-tapping screws as reinforcement, perpendicular to the grain, has been studied by Blass and Bejtka [2]. Parisi et al. [3] analyzed the use of small screws $(7-8 \mathrm{~cm})$ to prevent splitting near the joints of timber trusses. Tampone [4] studied the use of metal brackets, and several others [5-7] studied the application of metal braces. However, an important limitation is that metal elements are prone to oxidation and collapse in fires, as metals heat more readily than the timber.

Leijten [8] has found that local steel reinforcements (screws, bolts, etc.) inserted into timber members may lead to unexpected and unpredictable splitting, caused by the presence of hole clearance and by the stress concentration induced by the small diameter of the screws.

The use of composite materials for the reinforcement of existing timber members is not new [9-16]. Fiber-Reinforced Polymer (FRP) materials have been proven to have good tensile mechanical properties. Composite materials, especially glass and carbon reinforced polymer composites (GFRP and CFRP), are being progressively applied more in structural functions, not only for infrastructure or reinforcement 
of "modern" timber beams, but also for elements of architectural heritage. Usually, FRPs are applied where at least two of their valuable properties, e.g., high corrosion resistance and high tensile strength, may be exploited at the same time. In these situations, the total costs (material, application, and maintenance) of using composite materials are commensurate with traditional competitor materials, such as aluminum and steel, or with replacement. FRPs are usually applied using epoxy adhesives, inserted into pre-drilled holes, both in repair and in new-build applications. The bonded-in rod technology has been studied by Broughton and Hutchinson [17], and the conclusion that epoxy adhesives resulted in a satisfactory performance compared to acrylic, polyurethane, and phenol-resorcinol adhesives, with a pull-out strength increasing linearly with bondline thickness. Even if there have been considerable advancements in relation to the performance of polyurethane adhesives, the bond strengths and overall mechanical properties of epoxy adhesives are still superior.

However, the varied range of composite products and the scattered mechanical characteristics of FRP elements presently available can cause significant difficulties for the engineer who approaches this problem. For this reason, choice of the strengthening layout and material should be guided by a precise analysis of the characteristics of the timber element to be repaired or reinforced in order to avoid unsuccessful interventions. The long-term durability of some FRP products needs to be studied and demonstrated $[18,19]$.

The General Assembly of the United Nations proclaimed 2009 the International Year of Natural Fibers, but only very recently have researchers started to study the use of natural-based FRPs for applications in civil engineering. The aim of all major international organizations is to promote the efficiency and sustainability of natural fiber industries, and to encourage suitable policies from governments. However, there have been few studies to date on the use of natural fibers for the reinforcement of timber structures. Borri et al. studied the use of bamboo, flax, and basalt strips to enhance to capacity of timber beams [20]. De la Rosa et al. also analyzed the effect of basalt strip reinforcements applied to the tension side of timber beams [21]. Recently, Raftery et al. used bonded-in basalt FRP rods to strengthen and repair low-grade, glued, laminated timber beams [22].

This paper describes an experimental study of the use of basalt FRP (BFRP) spikes in timber beams to restore the continuity of cracked and damaged sections. The repair technique consists in the application of 95-mm-long BFRP spikes, inserted into diagonal holes, perforated in the timber beams at a center-to-center distance of $200 \mathrm{~mm}$. An artificially simulated cracking was produced by cutting the wood beams in half or notching them. A four-point-bending test was carried out on repaired and control timber beams, and results, in terms of bending capacity and modulus of elasticity, were compared to evaluate the effectiveness of the proposed repair technique. In comparison with the use of self-tapping screws, this procedure may be of interest because of the lower Young's modulus of the BFRP spikes (similar to the one of timber), and for lower stress concentrations based on the larger dimensions of BFRP spikes.

\section{Design of the Repair Technique}

An efficient solution is achieved when an effective joint is used to connect the two timber parts. An effective joint should be characterized by enough strength to transmit the shear loads developed at the interface and stiff enough to restrict the slip between the two elements. Two extreme situations are shown 
in Figure 1a: no connection (materials acting completely independent) and a perfect connection between the materials (full composite action). In the first case, slip occurs between the two timber elements resulting in two materials reacting independently to the bending loads and consequently to compressive and tensile stresses. In the second case, both elements are forced to act as a single element. The mechanical behavior of the joint has a significant importance for the behavior of the structure and it has a direct impact on the stress pattern as well as in its deformation mode.

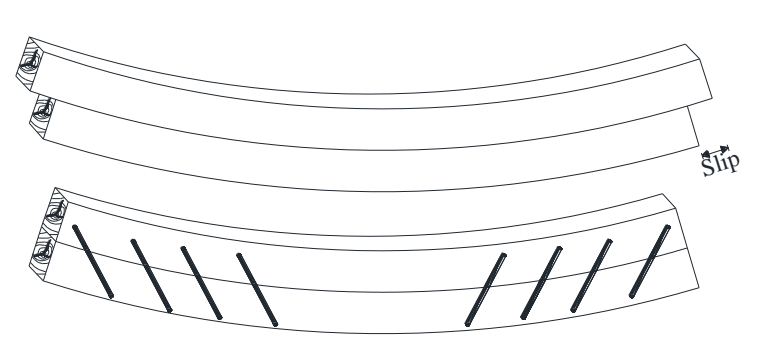

(a)

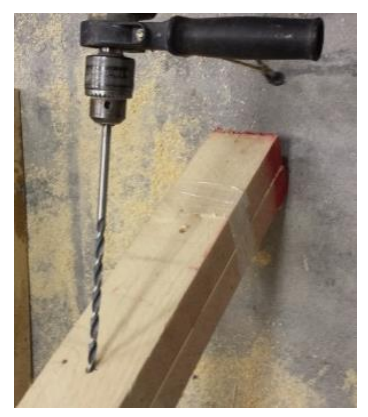

(b)

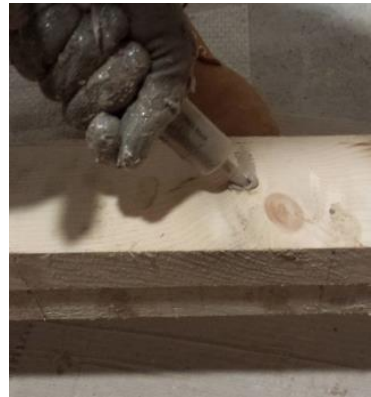

(c)

Figure 1. (a) Schematic arrangement of Basalt Fiber Reinforced Polymer (BFRP) spikes;

(b) Diagonal hole drilling; (c) Injection of epoxy putty.

In this investigation, eight BFRP spikes were inserted into diagonal holes $\left(45^{\circ}\right)$ drilled in the timber beams (Figure 1b) at a center-to-center distance of $200 \mathrm{~mm}$. The use of inclined spikes was chosen because several experimental and numerical studies have shown how the increase of screw inclination affords an increase of the resistance and stiffness of the joints [23,24]. No spikes were applied to the central part of the softwood beams where shearing force is equal to zero. Bi-component epoxy putty was injected inside the holes before inserting the BFRP spikes to facilitate the connection between timber and reinforcement (Figures $1 \mathrm{c}$ and 2). By considering that the spike and hole diameters were 6 and $8 \mathrm{~mm}$, the epoxy bond thickness was approximately $1 \mathrm{~mm}$.

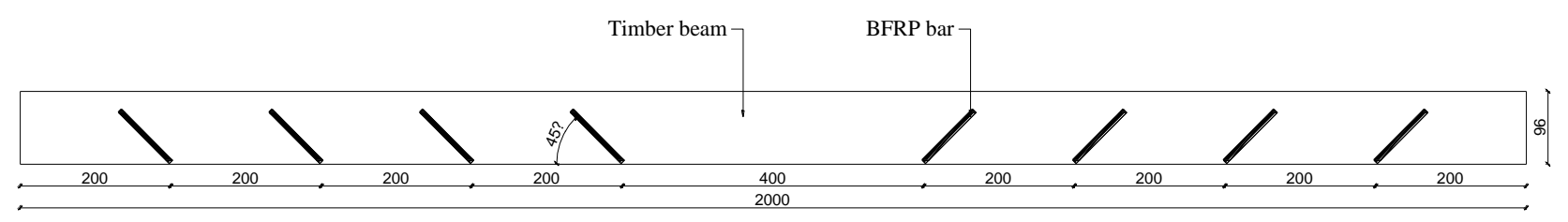

Figure 2. Layout of BFRP spikes (dimensions in (mm)).

In order to calculate the diameter $(d)$ of the spikes (Table 1), the Johansen yielding theory [25] was used and adapted. The Johansen approach identifies three different failure modes for a timber to timber joint: in the first mode (mode A), the final load-bearing capacity is obtained when the wood yields along the reinforcement (Figure 3); the second (mode B) is characterized by a combination of the embedment failure in the timber and a single yield failure in the connector. The last failure mode (mode $\mathrm{C}$ ) occurs when there is a combination of the embedment failure in the timber and a double yield failure in the connector. 


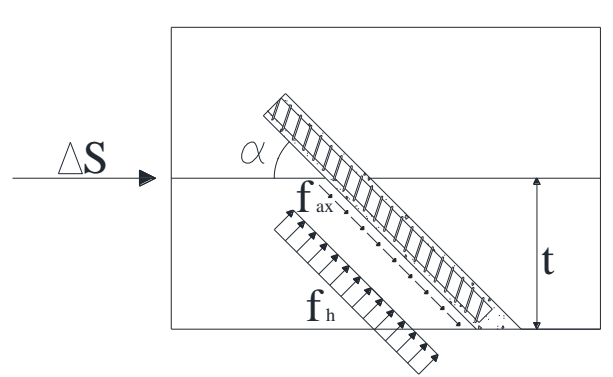

(a)

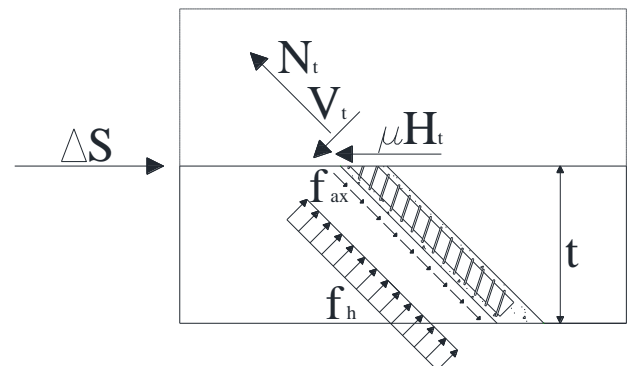

(b)

Figure 3. Failure mode A: (a) stresses in the joint; (b) load on the interface between the timber elements.

Table 1. Mechanical properties of the BFRP spikes.

\begin{tabular}{cccccc}
\hline $\begin{array}{c}\text { Nominal } \\
\text { Diameter }(\mathbf{m m})\end{array}$ & $\begin{array}{c}\text { Weight Density } \\
(\mathbf{k g} / \mathbf{m})\end{array}$ & $\begin{array}{c}\text { Failure } \\
\text { Load }(\mathbf{k N})\end{array}$ & $\begin{array}{c}\text { Tensile } \\
\text { Strength (MPa) }\end{array}$ & $\begin{array}{c}\text { Young's } \\
\text { Modulus (GPa) }\end{array}$ & $\begin{array}{c}\text { Strain at } \\
\text { Failure (\%) }\end{array}$ \\
\hline 6 & 0.452 & 21.5 & 761 & 36.56 & 2.08 \\
\hline
\end{tabular}

Due to the linear elastic response of BFRP spike, only the failure mode A was considered here. The ultimate load-bearing capacity can be evaluated from internal forces in the non-deformed state:

$$
\Delta S=N_{t} \cos \alpha+V_{t} \sin \alpha+\mu H_{t}
$$

where $N_{t}$ and $V_{t}$ are the axial and shearing forces applied on the spike, respectively; $H_{t}$ is the horizontal force at the interface between the two timber elements, $\mu$ is the coefficient of friction, $\alpha$ is the angle of inclination of the spike with respect to the grain direction (equal to $45^{\circ}$ ) and $\Delta S$ is the slip load at the interface between the two timber parts. Assuming a perfect connection between the two parts the slip load $\Delta S$ for a length $\Delta z$ (equal to $200 \mathrm{~mm}$ ) can be evaluated as:

$$
\Delta S=\frac{V_{E d} \times S_{x}}{I_{x}} \times \Delta z
$$

where $V_{E d}$ is the average shearing force, $S_{x}$ is the first moment and $I_{x}$ is the second moment of the beam cross section, respectively, calculated as:

$$
S_{x}=\frac{b \times h^{2}}{8}, \quad I_{x}=\frac{b \times h^{3}}{12}
$$

where $b$ is the width and $h$ is the height of the cross section.

The horizontal force is defined as:

$$
H_{t}=N_{t} \sin \alpha-V_{t} \cos \alpha
$$

The axial load $N_{t}$ acting on a BFRP spike can be calculated:

$$
N_{t}=\frac{f_{a x} \times d \times t}{\sin \alpha}
$$

where $d$ is the nominal diameter of the composite element, $t$ is the embedded length and $f_{a x}$ is the withdrawal strength of the timber, defined according to the Eurocode 5 [26] as: 


$$
f_{a x}=\frac{3.6 \times 10^{-3} \times \rho^{1.5}}{\sin ^{2} \alpha+1.5 \times \cos ^{2} \alpha}
$$

The lateral force acting on the BFRP spike can be evaluated:

$$
V_{t}=\frac{f_{h} \times d \times t}{\sin \alpha}
$$

where $f_{h}$ is the embedment strength for timber according with Eurocode 5 for timber with pre-drilled holes, based on a large number of embedding tests, and equal to:

$$
f_{h}=0.082 \times(1-0.01 \times d) \times \rho
$$

Substituting Equations (5) and (7) into the Equations (1) and (4), the following equation is obtained:

$$
\Delta S=f_{a x} \times d \times t \times(\cot \alpha+\mu)+f_{h} \times d \times t \times(1-\mu \times \cot \alpha)
$$

Assuming a coefficient of friction for the timber equal to 0.3 , the required spike's diameter is equal to $5.34 \mathrm{~mm}$ and according to the suitable commercial diameters, it was decided to use a 6-mm-diameter spike.

\section{Material Characterization}

\subsection{Timber}

All beams were made of softwood (fir-wood). Tests were carried out on sharp-edged timber beams (Figure 4a) in fir wood (Abies Alba). All the timber beams had the same width (96 mm), height (96 mm) and length $(2000 \mathrm{~mm})$. The average weight density and moisture content were $417 \mathrm{~kg} / \mathrm{m}^{3}\left(\mathrm{dev} .24 \mathrm{~kg} / \mathrm{m}^{3}\right)$ and $14.31 \%$ (dev. 0.89\%), respectively. Moisture content was measured according to EN 13183-1: 2002 standard [27].

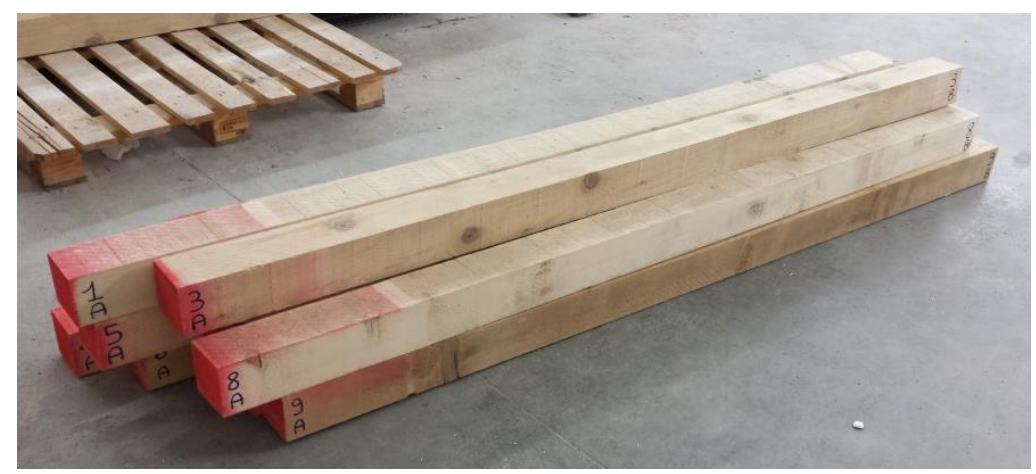

(a)

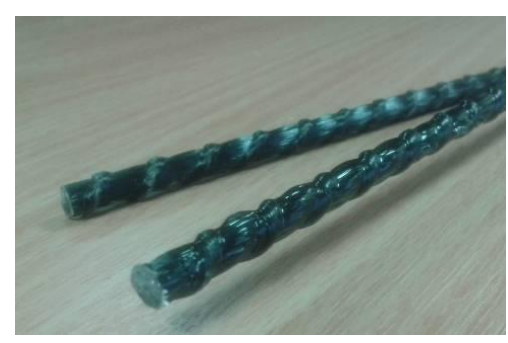

(b)

Figure 4. (a) Softwood beams; (b) BFRP spikes.

\subsection{BFRP Spikes}

Due to its anisotropic behavior, seasoning of timber always causes spit opening along the grain in structural timber beams. The prime objective of seasoning is to reduce the moisture content and increase mechanical properties. BFRP spikes (Figure $4 \mathrm{~b}$ ) were used here to restore the continuity of artificially damaged timber beams. 
For this purpose, fir wood beams, from the same batch, were artificially damaged. Eight beams were cut in half and six beams were partially notched. Two horizontal notches (35 mm long) were made along the entire longitudinal direction.

Six 6-mm-diameter spikes were tested in tension according to ASTM D3039 standard [28] and their strains recorded with a $50 \mathrm{~mm}$ gauge length mechanical extensometer. The average of the six coupon test values in given in Table 1. Tensile tests were first conducted to verify the ultimate strength and Young modulus given by the producer's data sheet. All spike specimens exhibited a linear elastic response and failed suddenly as expected. Test results show a tensile strength and Young's modulus of $761 \mathrm{MPa}$ and $36.56 \mathrm{GPa}$, respectively.

\subsection{Epoxy Putty}

To facilitate the connection between timber and BFRP spikes, a bi-component epoxy putty, manufactured by MAC Spa, was injected inside the pre-drilled holes. After the insertion of the spikes the epoxy system was cured for 10 days at room temperature.

Mechanical characteristics of the epoxy putty were evaluated by testing five specimens in compression and four in tension according to ASTM D695 [29] and D638 [30] standards, respectively. Test results are shown in Table 2.

Table 2. Mechanical properties of the epoxy putty.

\begin{tabular}{cc}
\hline Mechanical Property & Value \\
\hline Compressive Strength (MPa) & 65.54 \\
(Standard deviation) (MPa) & $(3.95)$ \\
Sample size & 5 \\
Tensile strength (MPa) & 25.21 \\
(Standard deviation) (MPa) & $(2.88)$ \\
Sample size & 4 \\
Young's modulus (GPa) & 4.58 \\
(Standard deviation) (GPa) & $(0.27)$ \\
\hline
\end{tabular}

\section{Test Setup and Test Results}

Five series of bending tests were performed on undamaged, damaged and repaired softwood beams (Table 3). Twenty-four beams were subjected to the four-point-bending test, according to UNI EN 408 standard [31]. The strength tests were carried out at a span length of $1728 \mathrm{~mm}$ and a distance between the loading heads of $576 \mathrm{~mm}$. In order to decrease the local crushing of the wood, the load was applied through two 42-mm-diameter solid steel cylinders. Displacement controlled loading ensued with a crosshead speed of $2 \mathrm{~mm} / \mathrm{min}$.

Load was applied monotonically until failure by means of a hydraulic cylinder connected by a circuit to a hand pump. The vertical displacement of the beams was recorded using three inductive transducers (LVDT). The bending strength $f_{m}$ was calculated according to:

$$
f_{m}=a \frac{F_{u}}{2 W}
$$


where $F_{u}$ is the maximum load; $a$ is the distance between the point of application of the load and the nearest support; $W$ is the modulus of resistance of the section. From these measured values and taking into account the cross-sectional dimensions of the timber beams, a global modulus of elasticity $E_{m, g}$ can be calculated with the following formulation:

$$
E_{m, g}=\frac{l^{3}\left(F_{2}-F_{1}\right)}{b h^{3}\left(w_{2}-w_{1}\right)}\left[\left(\frac{3 a}{4 l}\right)-\left(\frac{a}{l}\right)^{3}\right]
$$

where $l$ is the distance between the rollers; $F_{2}-F_{1}$ is an increment of load on the straight-line portion of the load deformation curve; $w_{2}-w_{1}$ is the increment of deformation corresponding to $F_{2}-F_{1} ; b$ is width of cross section. In order to have a overall information of the stiffness properties of the timber beams it was decided to measure and calculate only the global modulus of elasticity evaluated according to Equation (11). The test setup is shown in detail in Figure 5a.

Table 3. Test matrix.

\begin{tabular}{cccc}
\hline Index & Number of Beams & Timber Beam & Repair \\
\hline UNS_series & 10 & - & - \\
US_series & 3 & Cut in half & - \\
UN_series & 3 & Notched & - \\
RS_series & 5 & Cut in half & BFRP spike \\
RN_series & 3 & Notched & BFRP spike \\
\hline
\end{tabular}

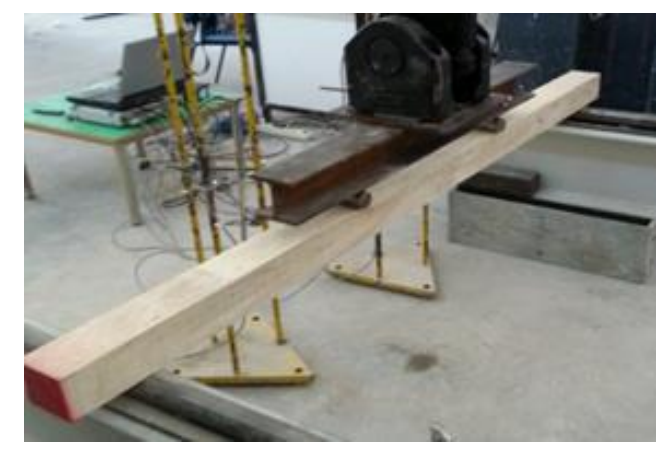

(a)

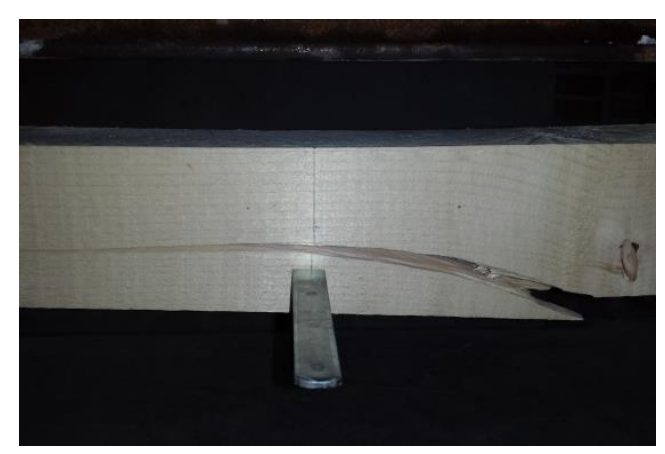

(b)

Figure 5. (a) Four-point-bending test setup; (b) Typical tensile failure mode of control beams near a knot or due to grain deviation.

\subsection{Control Beams}

Fourteen control beams were subjected to flexure in four-point-bending. These results have been reported only for the purpose of quantitatively calculating the effectiveness of the repair intervention through a comparison with the results of identical tests performed on the strengthened beams. Various modes of fracture were detected in the timber beams, but all on the tension side: simple tension, cross grain tension, knot influenced (Figure 5b). Knots and grain deviation highly influenced the propagation of the cracks for all control specimens. Deflection characteristics of the tested control beams are shown in Table 4, the average bending strength was $24.5 \mathrm{MPa}(\mathrm{dev}$. 8.3 MPa) and the global modulus of elasticity was $5932 \mathrm{MPa}$ (dev. $907 \mathrm{MPa}$ ). 
Table 4. Test results (control beams).

\begin{tabular}{cccccc}
\hline $\begin{array}{c}\text { Timber Beam } \\
\text { Condition }\end{array}$ & Index & $\begin{array}{c}\text { Maximum } \\
\text { Load }(\mathbf{k N})\end{array}$ & $\begin{array}{c}\text { Bending } \\
\text { Strength (MPa) }\end{array}$ & $\begin{array}{c}\text { Global Modulus of } \\
\text { Elasticity (MPa) }\end{array}$ & $\begin{array}{c}\text { Deflection at } \\
\text { Max Load (mm) }\end{array}$ \\
\hline & UNS_1 & 13.0 & 26.2 & 6077 & 37.0 \\
& UNS_2 & 7.5 & 15.2 & 5148 & 23.5 \\
& UNS_3 & 14.8 & 29.9 & 6825 & 36.5 \\
& UNS_4 & 8.6 & 17.2 & 6029 & 21.4 \\
Undamaged & UNS_5 & 15.7 & 31.6 & 5668 & 60.3 \\
Beams & UNS_6 & 12.7 & 25.5 & 4684 & 36.2 \\
& UNS_7 & 16.8 & 33.8 & 7059 & 45.5 \\
& UNS_8 & 15.5 & 31.2 & 7059 & 32.5 \\
& UNS_9 & 12.9 & 26.0 & 6158 & 29.2 \\
& UNS_10 & 4.1 & 8.18 & 4611 & 12.6 \\
& Average & 12.1 & 24.5 & 5932 & 33.5 \\
& (St. deviation) & $(4.1)$ & $(8.3)$ & $(907)$ & $(13.3)$ \\
\hline \multirow{5}{*}{ Notched } & UN_1 & 6.8 & 13.5 & 6137 & 16.3 \\
beams & UN_2 & 9.8 & 19.9 & 5657 & 28.6 \\
& UN_3 & 8.3 & 16.6 & 5073 & 21.0 \\
& Average & 8.3 & 16.7 & 5622 & 22.0 \\
& (St. Deviation) & $(1.3)$ & $(2.6)$ & $(435)$ & $(5.0)$ \\
\hline \multirow{6}{*}{ Beams cut } & US_1 & 6.5 & 12.8 & 1112 & 81.0 \\
in half & US_2 & 6.1 & 11.9 & 1141 & 72.7 \\
& US_3 & 6.5 & 13.0 & 1203 & 71.0 \\
& Average & 6.4 & 12.5 & 1152 & 74.9 \\
& (St. Deviation) & $(0.18)$ & $(0.47)$ & $(38.0)$ & $(4.39)$ \\
\hline
\end{tabular}

Load-displacement curves (Figure 6a) are initially linear. As the load increases, timber begins to yield in the compression zone and failure occurs in the tension zone when the tensile strength is reached. Three beams (UNS_2; UNS_4 and UNS_10) exhibited an early failure influenced by the presence of a large defect (knot) in the tension side (Figure 5b). The scatter in the capacity values of control beams, where the presence of grain deviation and knots influence the failure mode, is very high.

Six beams were subjected to four-point-bending after being artificially damaged: three timber beams were divided in-half and three were cut with two $35 \mathrm{~mm}$ horizontal notches (Figure 7). The control notched specimens (UN_1, UN_2 and UN_3) exhibited an average bending strength of 16.7 MPa and a global modulus of elasticity of $5622 \mathrm{MPa}$. Furthermore the failure of these specimens occurred in the area where bending moment is maximum. Fracture was influenced by the presence of the two notches: beams UN_1 and UN_3 failed due to separation of upper part half from lower half and subsequent tensile failure in tension side. This caused a significant reduction in beam capacity shifting from 12.1 (undamaged beams) to $8.3 \mathrm{kN}$ (notched beams):

The control specimens that were cut in half (US_1, US_2 and US_3) exhibited an average bending strength of $12.5 \mathrm{MPa}$ and a global modulus of elasticity of $1152 \mathrm{MPa}$, with a reduction compared to undamaged beams of approximately $49 \%$ and $87 \%$, respectively. Failure emerged in proximity of the application point of the load at the tension side. A significant slippage of the two parts of the beams was 
clearly recorded during the tests. All the artificially damaged (cut in half and notched timber beams) usually showed an elastic-linear response up until the failure (Figure 6b).

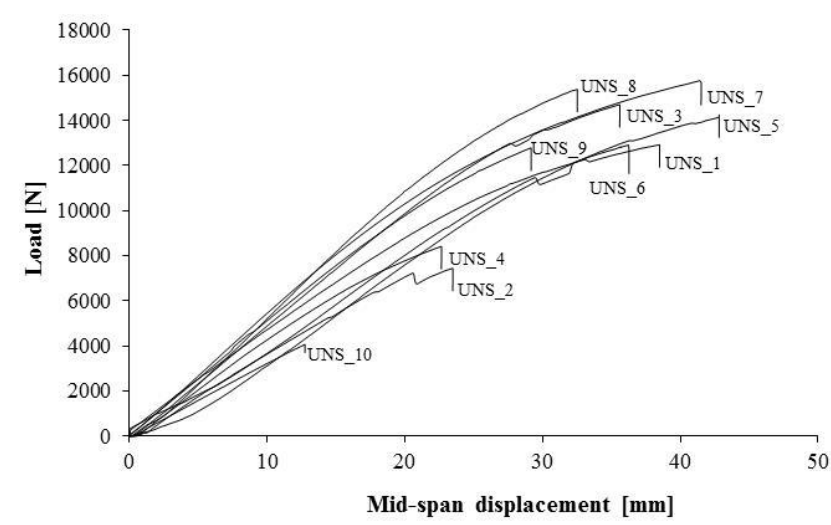

(a)

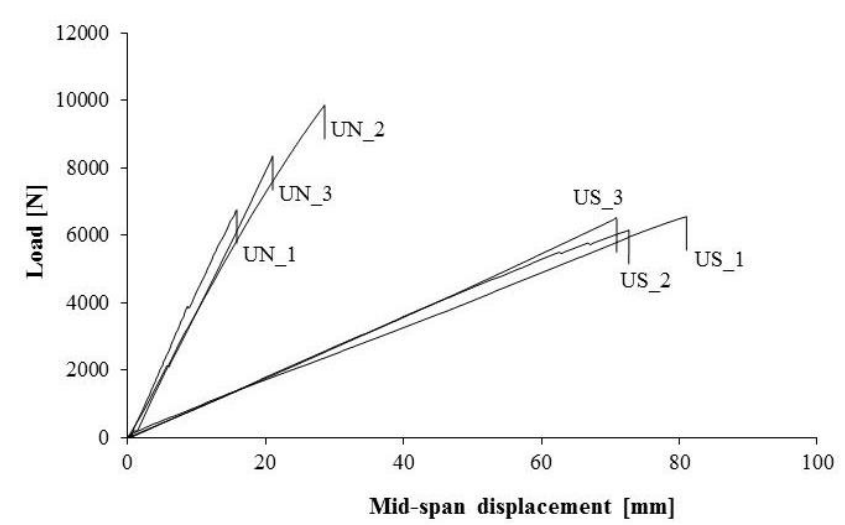

(b)

Figure 6. Load-Displacement curves: (a) control un-damaged beams; (b) beams that were cut in half or notched.

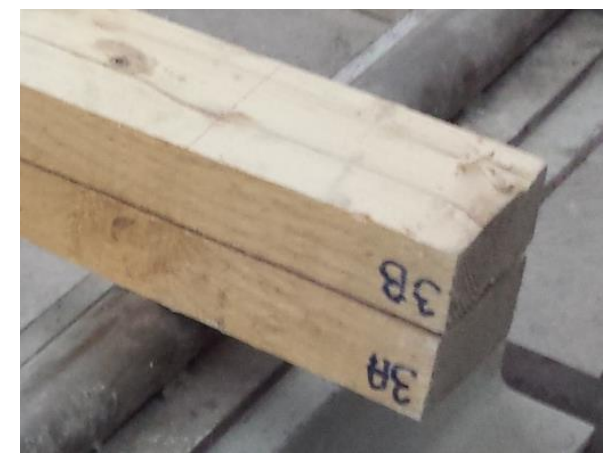

(a)

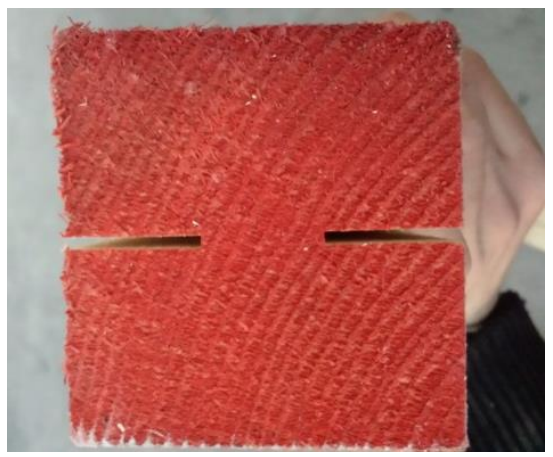

(b)

Figure 7. (a) Timber beams cut in half; (b) Notched beams.

\subsection{Repaired Beams}

BFRP spikes have been applied to cut-in-half (Figure 7a) and to notched beams (Figure 7b) with the aim to restore the continuity of damaged timber beams.

Three repaired notched beams were tested (RN_1, RN_2 and RN_3) and test results are reported in Table 5. The application of the BFRP spikes produced an increase of the average bending strength of $56.1 \%$ and of the global modulus of elasticity of $19 \%$ compared to the control notched beams (Table 6). Both for control and repaired beams, an elastic response has been recorded. The main result is that timber beams did not fail due to separation of the upper from the beam's lower part near the notches, but beams exhibited tensile timber failures initiated by defects (mainly grain deviation and knots). The deviation in the strength value of beams, also considering the limited number of tests performed, is also relatively low. Furthermore, it can broadly be said that the repaired notched beams allow the achievement of the bending capacity and stiffness of the control and undamaged beams. 
Table 5. Test results (repaired beams).

\begin{tabular}{ccccc}
\hline Index & $\begin{array}{c}\text { Maximum } \\
\text { Load }(\mathbf{k N})\end{array}$ & $\begin{array}{c}\text { Bending } \\
\text { Strength (MPa) }\end{array}$ & $\begin{array}{c}\text { Global Modulus of } \\
\text { Elasticity (MPa) }\end{array}$ & $\begin{array}{c}\text { Deflection at } \\
\text { Maximum Load (mm) }\end{array}$ \\
\hline RS_1 & 9.91 & 19.4 & 5855 & 73.8 \\
RS_2 & 5.11 & 9.97 & 6250 & 29.2 \\
RS_3 & 5.29 & 10.5 & 3136 & 48.4 \\
RS_4 & 9.68 & 18.7 & 5377 & 71.0 \\
RS_5 & 8.28 & 16.5 & 3900 & 54.2 \\
Average & 7.65 & 15.0 & 4904 & 55.3 \\
(St. Deviation) & 2.08 & 4.02 & 1189 & 16.2 \\
\hline RN_1 & 12.4 & 29.8 & 7524 & 29.8 \\
RN_2 & 13.6 & 27.2 & 6233 & 28.8 \\
RN_3 & 10.5 & 21.0 & 6327 & 51.0 \\
Average & 12.2 & 26.0 & 6695 & 36.5 \\
(St. Deviation) & 1.29 & 3.73 & 588 & 10.3 \\
\hline
\end{tabular}

Table 6. Results of control and repaired beams.

\begin{tabular}{cccccc}
\hline Index & Repaired & Condition & $\begin{array}{c}\text { Maximum } \\
\text { Load (kN) }\end{array}$ & $\begin{array}{c}\text { Bending } \\
\text { Strength (MPa) }\end{array}$ & $\begin{array}{c}\text { Deflection at } \\
\text { Maximum Load (mm) }\end{array}$ \\
\hline UNS_series & No & - & 12.1 & 24.5 & 33.5 \\
US_series & No & Notched & 6.40 & 12.5 & 71.0 \\
UN_series & No & Cut-in-half & 8.32 & 16.7 & 22.0 \\
RN_series & Yes & Notched & 12.2 & 26.0 & 36.5 \\
RS_series & Yes & Cut-in-half & 7.65 & 15.0 & 55.3 \\
\hline
\end{tabular}

The repaired cut-in-half beams (RS_1, RS_2, RS_3, RS_4 and RS_5) exhibited an average bending strength of 15.0 MPa and a global modulus of elasticity of $4904 \mathrm{MPa}$. Failure, again knot influenced, occurred in the timber material on the tension side where the bending moment is maximal. After timber failure, the BFRP spikes did not exhibit any damage, but partially separated from the epoxy resin in the holes. Slippage was also generated by timber shear failure near the holes caused by the low shear strength of fir wood (Figure 8). Figure 9 shows the load-deflection response of control and repaired beams that were cut in half. The load-displacement graphs generally show that there is a large amount of vertical mid-span deflection even for low loads due to the slippage of the BFRP spikes.

After an initial elastic phase, repaired beams (RS_series) exhibited a plastic behavior. Increases of bending strength compared to control beams were limited due to low quality of timber material (fir wood) and separation of BFRP spikes from the epoxy resin. Beams RS_2 and RS_3 collapsed for a low bending load due the presence of a large knot defect in timber tension zone. The insertion of the BFRP spikes resulted in moderate enhancements in the beam ultimate capacity $(+19.8 \%)$ while more significant improvements in the stiffness were obtained $(+325.7 \%)$ and it is essentially due to the low values of stiffness of cut-in-half beams. However, the insertion of the BFRP spikes did not cause the achievement of the values of the control timber beams in terms of bending capacity and stiffness.

Another interesting feature of the load-deflection curves is that repaired specimens after an initial decrease of the load due to a beam cracking, were able to withstand a further increase in load. The BFRP repaired beams demonstrated an initial linear elastic behavior and exhibited brittle timber tensile-flexural 
failures on the lower half of the timber beam when subject to flexural loading. After this, a pseudo-ductile behaviour of the repaired beams has been recorded.

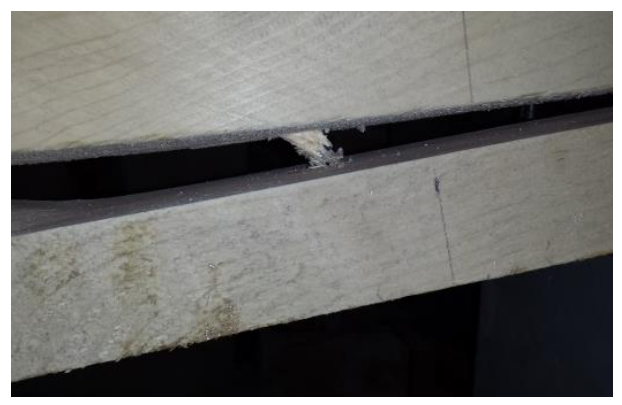

Figure 8. Pull out of the BFRP spike.

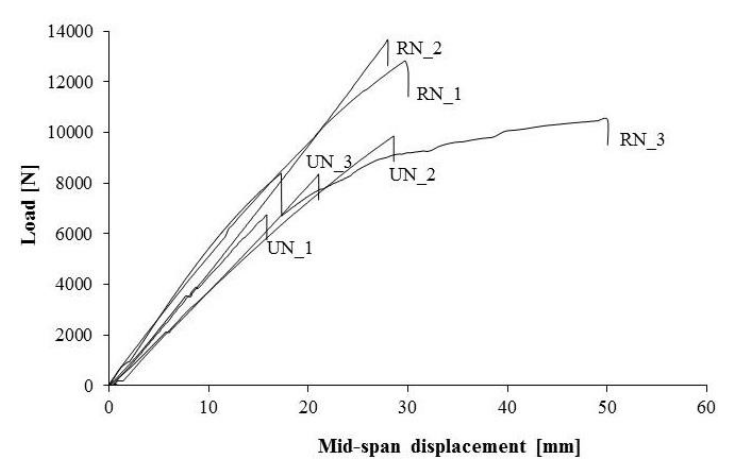

(a)

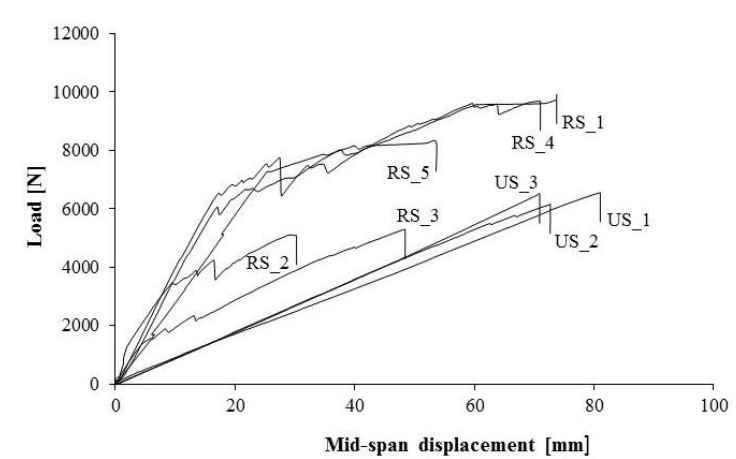

(b)

Figure 9. Load-Displacement curves: (a) control (US-series) and repaired (RS-series) beams cut in half, notched beams; (b) control (UN-series) and repaired (RN-series) beams that were cut in half.

For both notched and cut-in-half beams, experimental testing in flexure has demonstrated that the insertion of BFRP spikes incorporating basalt fiber reinforcement epoxy-bonded onto softwood (low-grade) beams can increase the beam capacity and stiffness and introduce pseudo-ductile behavior into the hybrid beams in comparison with the linear elastic brittle tensile failure experienced by the control beams (Figure 10). However, this non-linear behavior was mainly caused by slippage phenomena of the BFRP spikes demonstrating the limited effectiveness of these epoxy-bonded connections.

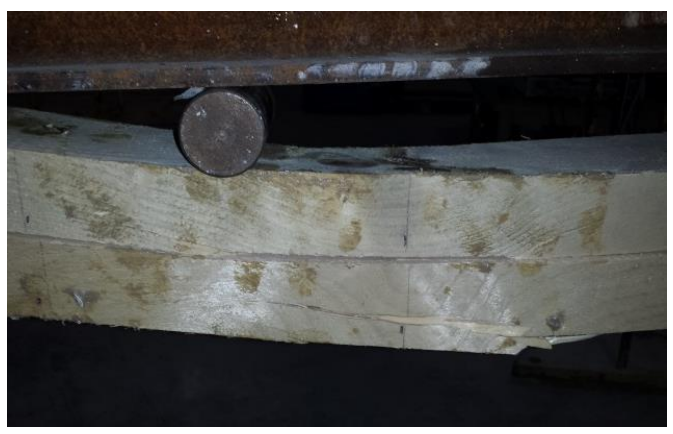

(a)

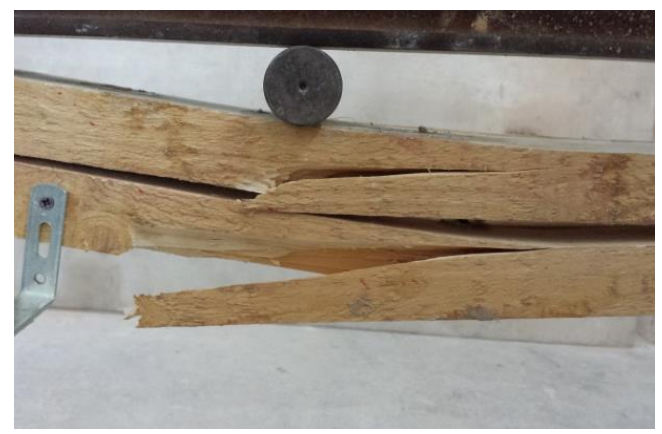

(b)

Figure 10. Timber tensile-flexural failures (beams that were cut in half): (a) in the lower half; (b) both in the lower and upper half. 


\section{Conclusions}

This article illustrates an experimental study of the effect of BFRP spikes to restore continuity of softwood (fir-wood) cracked beams. The following conclusions can be drawn:

(1) Various modes of fracture were detected for the control beams, but all on the tension side: simple tension, cross grain tension, knot influenced. Knots and grain deviation highly influenced the propagation of the cracks for all control specimens and were the main cause of beam's failure.

(2) For both notched and cut-in-half beams, experimental testing in flexure has demonstrated that the insertion of BFRP spikes incorporating basalt fiber reinforcement epoxy-bonded onto softwood (low-grade) beams can increase beam capacity and stiffens and introduces pseudo-ductile behavior into the hybrid beams in comparison with the linear elastic brittle tensile failure experienced by the control beams.

(3) Bending test results indicate that the application of the proposed BFRP spikes partially recaptures both bending stiffness and load capacity of the "undamaged" beams. Enhanced repair performance is directly related to the mechanical properties of the substrate (timber material).

(4) Slippage phenomena of the BFRP spikes demonstrated a limited effectiveness of epoxy-bonded connections as slippage was generated by both resin and timber shear failures, the latter caused by the poor mechanical properties of fir wood.

(5) It is evident that the addition of the epoxy adhesive in the grooves has a strong effect on the success of the proposed repair method. Without the epoxy adhesive, spike slippage is highly facilitated. However, this problem could not be completely solved as a slippage was noted during the bending tests.

\section{Acknowledgments}

The authors would like to acknowledge the support of the Structural Engineering Laboratory at Perugia University for the use of test and measurement equipment critical to the collection and evaluation of the data presented. The experimental program was carried out with the help of Alessandro Maraca, undergraduate student, and Alessio Molinari, Graduate Research assistant. Authors are also grateful for contribution to the research to Antonio Del Mastro. BFRP spikes were supplied by Aldebran srl (www.materialicompositi.com).

\section{Author Contributions}

Marco Corradi and Antonio Borri conceived and designed the experiments; Luca Righetti performed the experiments; Marco Corradi and Luca Righetti analyzed the data; Luca Righetti wrote the paper.

\section{Conflicts of Interest}

The authors declare no conflicts of interest. 


\section{References}

1. Federal Highway Administration. Seventh Annual Report to The Congress on Highway Bridge Replacement and Rehabilitation. US Department of Transportation: Washington, DC, USA, 1986.

2. Blass, H.J.; Bejtka, I. Reinforcement perpendicular to the grain using self-tapping screws. In Proceedings of the 8th World Conference on Timber Engineering, Lahti, Finland, 14-17 June 2014.

3. Parisi, M.A.; Cordiè, C.; Piazza, M. Adeguamento Sismico delle Capriate Lignee: I metodi di rinforzo tradizionali. In Proceedings of the 12th Conference ANIDIS, Pisa, Italy, 10-14 June 2007. (In Italian)

4. Tampone, G. Il restauro delle Strutture di Legno, 1st ed.; Hoepli Editore: Milano, Italy, 1996; p. 170. (In Italian)

5. Kent, S.M.; Gupta, R.; Miller, T.H. Dynamic behavior of metal-plate-connected wood truss joints. J. Struct. Eng. 1997, 123, 1037-1045.

6. Burdzik, W.M.G.; Skorpen, S.A. Metal-strip bracing versus diagonal timber bracing in timber trussed tiled roofs. Eng. Struct. 2014, 75, 1-10.

7. Palma, P.; Garcia, H.; Ferreira, J.; Appleton, J.; Cruz, H. Behaviour and repair of carpentry connections-Rotational behaviour of the rafter and tie beam connection in timber roof structures. J. Cult. Herit. 2012, 13, S64-S73.

8. Leijten, A.J.M. Locally reinforced timber joints with expanded tube fasteners. HERON 1999, 44, 131-161.

9. Radford, D.W.; van Goethem, D.; Gutkowsi, R.M.; Peterson, M.L. Composite repair of timber structures. Constr. Build. Mater. 2002, 16, 417-425.

10. Gentile, C.; Svecova, D.; Rizkalla, S.R. Timber beams strengthened with GFRP Bars: Development and application. J. Compos. Constr. 2002, 6, 11-20.

11. Borri, A.; Corradi, M.; Grazini, A. A method for flexural reinforcement of old wood beam with CFRP materials. Compos. B Eng. 2005, 36, 143-153.

12. Micelli, F.; Scialpi, V.; la Tegola, A. Flexural reinforcement of glulam timber beams and joints with carbon fiber-reinforced polymer rods. J. Compos. Constr. 2005, 9, 337-347.

13. Raftery, G.M.; Whelan, C. Low-grade glued laminated timber beams reinforced using improved arrangements of bonded-in GFRP rods. Constr. Build. Mater. 2014, 52, 209-220.

14. Lopez-Anido, R.; Hu, H. Structural characterization of hybrid FRP-Glulam panels for bridge decks. J. Compos. Constr. 2002, 6, 194-203.

15 Corradi, M.; Borri, A. Fir and chestnut timber beams reinforced with GFRP pultruded elements. Compos. B Eng. 2007, 38, 172-181.

16 Jankowski, L.J.; Jasieńko, J.; Nowak, T.P. Experimental assessment of CFRP reinforced wooden beams by 4-point bending tests and photoelastic coating technique. Mater. Struct. 2010, 43, 141-150.

17 Broughton, J.G.; Hutchinson, A.R. Adhesive systems for structural connections in timber. Int. J. Adhes. Adhes. 2001, 21, 177-186.

18 Tascioglu, C.; Goodell, B.; Lopez-Anido, R.; Peterson, M.; Halteman, W.; Jellison, J. Monitoring fungal degradation of E-glass/phenolic fiber reinforced polymer (FRP) composites used in wood reinforcement. Int. Biodeterior. Biodegrad. 2003, 51, 157-165. 
19 Borri, A.; Castori, G.; Corradi, M.; Speranzini, E. Durability analysis for FRP and SRG composites in civil applications. Key Eng. Mater. 2015, 624, 421-428.

20 Borri, A.; Corradi, M.; Speranzini, E. Reinforcement of wood with natural fibers. Compos. B Eng. 2013, 53, 1-8.

21 De la Rosa García, P.; Escamilla, A.C.; García, M.N.G. Bending reinforcement of timber beams with composite carbon fiber and basalt fiber materials. Compos. B Eng. 2013, 55, 528-536.

22 Raftery, G.; Kelly, F. Basalt FRP rods for reinforcement and repair of timber. Compos. B Eng. 2015, 70, 9-19.

23 Blass, H.J.; Bejtka, I. Screws with continuous threads in timber connections. In Proceedings of Joints in Timber Structures, Stuttgart, Germany, 12-14 September 2001.

24 Kevarinmäki, A. Joints with inclined screws. In Proceedings of 35th CIB-Meeting, Kyoto, Japan, 16-19 September 2002.

25 Johansen, K.W. Theory of timber connections. Int. Assoc. Bridge Struct. Eng. 1949, 9, 249-262.

26 Eurocode 5 Design of Timber Structures Part 1-1: General-Common Rules and Rules for Buildings; EN 1995-1-1:2004; European Committee for Standardization: Brussels, Belgium, 2004.

27 Moisture Content of a Piece of Sawn Timber; BS EN 13183-2:2002; British Standards Institute: London, UK, 2002.

28 Standard Test Method for Tensile Properties of Polymer Matrix Composite Material; ASTM D3039; ASTM: West Conshohocken, PA, USA, 2014.

29 Standard Test Method for Compressive Properties of Rigid Plastics; ASTM D695; ASTM: West Conshohocken, PA, USA, 2014.

30 Standard Test Method for Tensile Properties of Plastics; ASTM D638; ASTM: West Conshohocken, PA, USA, 2014.

31 Timber Structures. Structural Timber and Glued Laminated Timber: Determination of Some Physical and Mechanical Properties; BS EN 408:2010; British Standards Institute: London, UK, 2002.

(C) 2015 by the authors; licensee MDPI, Basel, Switzerland. This article is an open access article distributed under the terms and conditions of the Creative Commons Attribution license (http://creativecommons.org/licenses/by/4.0/). 